\title{
SISTEM PENGENDALIAN GENERATOR SET SECARA WIRELESS BERBASIS ARDUINO DENGAN MODBUS TCP DAN LOGIKA FUZZY
}

\author{
Lutfianto $^{1}$, Faqih Rofi'i ${ }^{2}$, Moch. Mukhsim ${ }^{3}$ \\ Teknik Elektro, Fakultas Teknik \\ Universitas Widyagama, Malang, Indonesia \\ e-mail : 1lutfiafel@gmail.com,2faqih@widyagama.ac.id,307.mukhsin@gmail.com \\ Diterima: 18 April 2018. Disetujui : 15 Juni 2018. Dipublikasikan : 29 Juni 2018 \\ (C)2018 -TESJ Fakultas Teknik Universitas Maarif Hasyim Latif. Ini adalah artikel dengan \\ akses terbuka di bawah lisensi CC BY 4.0 (https://creativecommons.org/licenses/by/4.0/)
}

\begin{abstract}
ABSTRAK
Sistem pengendalian generator set secara wireless berbasis arduino dengan logika fuzzy adalah alat yang mempunyai sistem dengan kemampuan untuk mengontrol dan memonitor generator set dari lokal maupun dari jarak jauh melalui jaringan wifi dengan protokol modbus TCP. Kemampuan lain yang dimiliki alat tersebut adalah dapat menstabilkan putaran mesin penggerak dan tegangan keluaran generator yang berbasiskan kontroler logika fuzzy, sebagai generator set protection sistem dan sebagai back-up power sistem jika jaringan listrik mati. Sistem kontrol tersebut dirancang dari Arduino Mega 2560, arduino nano, GLCD 128X64, optocoupler, modul step down LM 2596. Dan wifi router TL-MR 2030. Tenaga yang dihasilkan maksimum 800 watt dengan tegangan 220 Volt $\mathrm{AC} \pm 5 \%$ dengan frekuensi $50 \mathrm{~Hz} \pm 5 \%$, dan dapat dikendalikan dari jarak maksimum 20 meter menggunakan jaringan wifi.
\end{abstract}

Kata kunci : arduino, automatic voltage regulator, generator set, logika fuzzy, modbus, wireless

\section{PENDAHULUAN}

Seiring dengan perkembangan jaman dan pesatnya pertumbuhan teknologi, kebutuhan akan sumber listrik terus meningkat dimanapun kita berada sehingga diperlukan sebuah generator set portabel yang dapat menyediakan kebutuhan listrik tersebut dengan fitur yang dapat dikontrol secara lokal maupun dari jarak jauh, mempunyai kesetabilan tegangan dan frekuensi yang konstant, dapat dimanfaatkan sebagai stanby power di saat pemadaman listrik, dapat melakukan start stop, dapat mengambil dan melepas beban, dapat menyesuaikan tegangan dan frekuensi dari keluaran generator set secara otomatis.

Kesetabilan frekuensi keluaran dari generator set dapat dipengaruhi oleh beban yang diterima oleh generator set yang berubah (Arifin, 2011). Untuk menjaga kesetabilan frekuensi keluaran, salah satu cara yang digunakan mengatur kecepatan putaran rotor tetap konstan walaupun terdapat perubahan beban (Wu, 2015). Dengan demikian maka frekuensi dari keluaran generator set akan stabil (Nursalim \& Soeprijanto, 2015). Agar tegangan keluaran dari generator tetap konstan, salah satu cara yang digunakan adalah pengaturan phase dari keluaran generator yang diatur oleh Automatic Voltage regulator (AVR) yang berbasis logika (Gupta \& Sambariya, 2017). Untuk memonitor parameter dari lokal kontrol digunakanlah GLCD dengan menggunakan Arduino Nano sebagai kontrol. Sedangkan untuk memonitor parameter generator set dari remote digunakanlah sistem modbus (Li, Zhang, Niu, \& Zhang, 2012). Agar generator set dan pemakai dapat terlindungi maka diperlukan sistem proteksi generator set. Sistem proteksi tersebut dipakai dengan tujuan untuk mengurangi resiko kerusakan dini generator set. Untuk keperluan stanby power, maka fitur automatic start dan stop sangat diperlukan, dengan tujuan untuk menyediakan daya listrik sementara jika terjadi pemadaman listrik. Wireless sistem yang digunakan untuk mentransfer data melalui protokol modbus menggunakan teknologi wifi yang berbasis $2.4 \mathrm{Ghz}$, sehingga pengontrolan dengan jarak jauh dapat dilakukan. Sebagai pengontrol generator set dari jarak dekat, digunakanlah device yang disebut dengan local kontrol panel. Dengan adanya lokal kontrol panel ini, maka sangat membantu sekali dalam memonitor parameter dari dekat generator (Ren, Ni, Pang, Li, \& Song, 2013).

\section{METODE PENELITIAN}

\section{Perancangan sistem power supply}

Perancangan sistem catu daya dibagi dalam tiga kelompok yaitu: regulator pengisian battery, modul step down dari 12 volt DC ke 7,5 volt DC dan modul step down dari 12 volt DC ke 5 volt DC. 
Sistem regulator pengisian dibangun dari transistor 2N 3055 dan dengan IC Regulator LM 317T adjustable.

Perancangan sistem penurun tegangan (step down) tegangan dari 12 volt DC ke 7,5 volt dan dari 12 Volt ke 5 volt digunakanlah modul LM 2956.

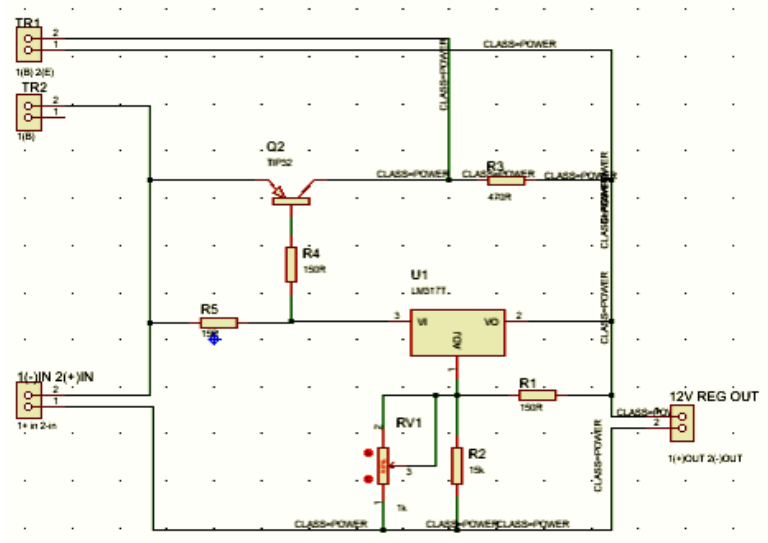

Gambar 1. Skematik regulator pengisian

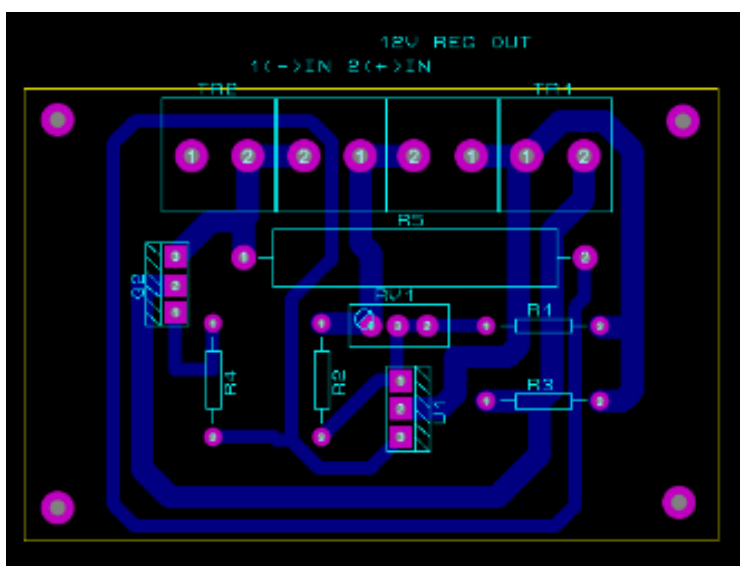

Gambar 2. PCB regulator pengisian

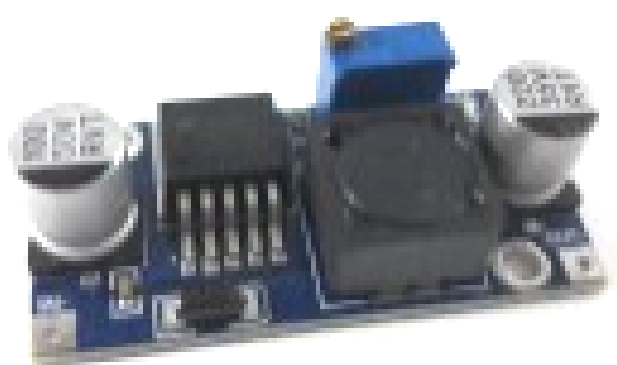

Gambar 3. LM 2956

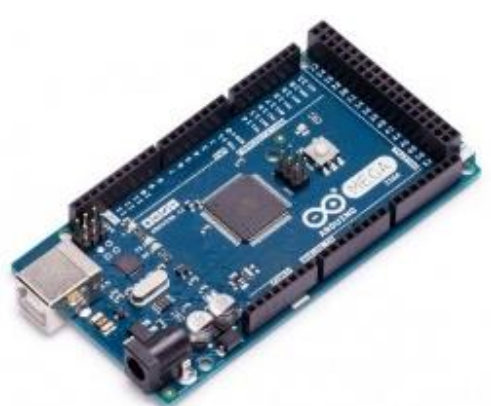

Gambar 4. Arduino Mega 2560

\section{Sistem pengontrol generator set}

Rancang bangun pengontrol generator set terdiri dari dua kelompoksistem kontrol yaitu sistem pengontrol mesin penggerak dan pengontrol sistem generator set.

\section{Sistem pengontrol mesin penggerak}

Rancang bangun Sistem pengontrol mesin penggerak ini dibangun dari Arduino mega 2560 dengan memanfaatkan pin analog dan digital. Keuntungan menggunakan Arduino Mega 2560 adalah tersedianya pin masukan dan keluaran yang cukup banyak.

Sebagai interface antara operator dengan Arduino Mega 2560 maka digunakan tombol sebagai perintah untuk mengontrol mesin penggerak. Agar keluaran dari Arduino mega 2560 dapat mengontrol mesin penggerak maka Arduino Mega harus diprogram sesuai alur program yang direncanakan.

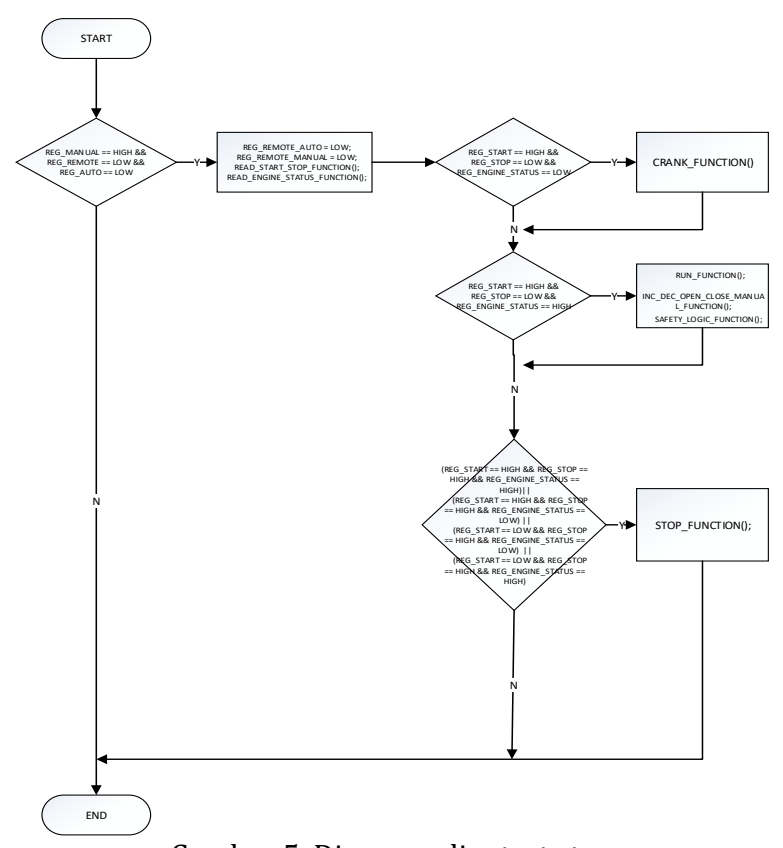

Gambar 5. Diagram alir start stop

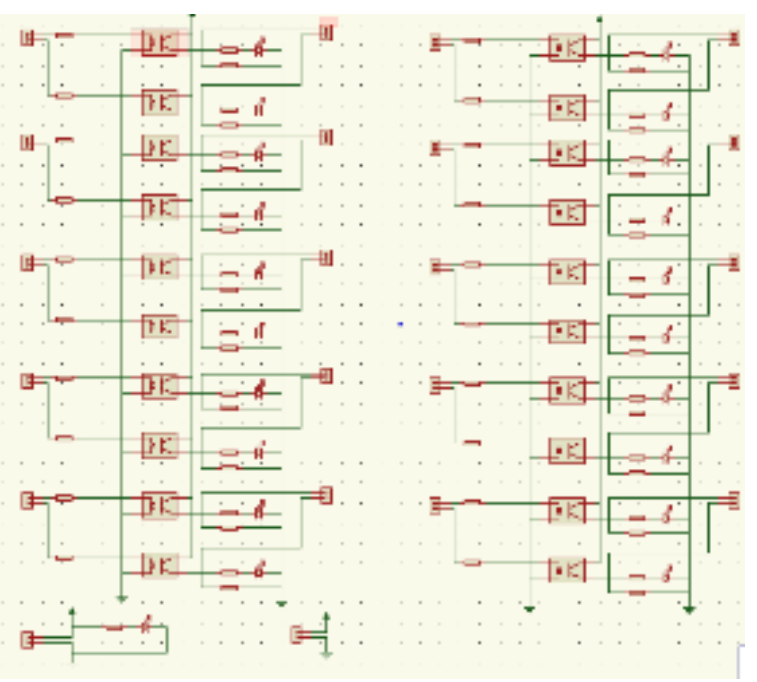

Gambar 6. Schematik isolator 
Untuk mengamankan Arduino Mega 2560 dari gangguan tegangan dari luar maka digunakanlah rangkaian isolator yang dibangun dari optocoupler. Sifat dari rangkaian ini adalah memisahkan antara sinyal yang keluar dari Arduino dan keluaran.



Gambar 7. PCB Isolator

Selain untuk memisahkan antara sinyal dari masukan dan keluaran, isolator juga berfungsi sebagai filter sinyal masukan.

\section{Sistem pengontrol generator}

Sistem pengontrol generator dirancang menjadi satu board arduino dengan kontrol mesin penggerak, keluaran dari kontrol generator juga dimasukkan ke isolator.

Perbedaan utama dari kontrol generator dan mesin penggerak adalah terletak di program yang ditanamkan didalam Arduino tersebut. Kontrol genertor dirancang dapat mengeluarkan sinyal untuk indikator tentang status dari main contact breaker.



Gambar 8. Diagram alir main breaker kontrol

\section{Sistem lokal kontrol panel}

Sistem lokal kontrol panel dirancang dengan tujuan untuk display dari semua parameter generator set. Untuk memenuhi kebutuhan tersebut maka lokal kontrol panel dirancang dari Graphic Liquid Crystal Display (GLCD) dengan resolusi $128 \times 64$.

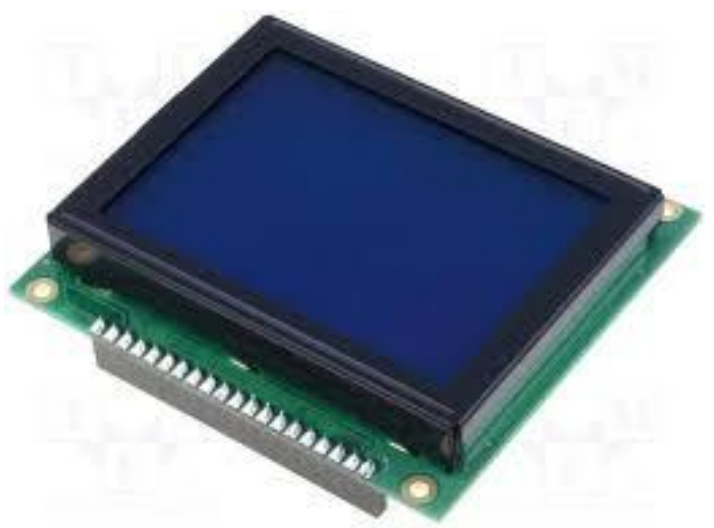

Gambar 9. Graphic LCD 128 x 64



Gambar 10. Arduino nano

Sedangkan sebagai kontrol agar GLCD dapat menampilkan graphic yang sesuai dengan rancangan maka digunakanlah Arduino Nano sebagai kontrol yang didalamnya ditanan program dengan menggunakan library arduino U8glib yang ditulis oleh Olikraus, dan dapat diunduh di https://github.com/olikraus/u8glib secara gratis. Pada Gambar 11 adalah diagram blok sistem lokal kontrol panel.

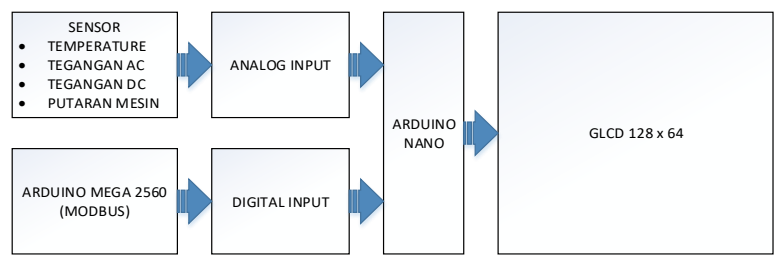

Gambar 11. Diagram blok lokal kontrol panel

Agar pemrograman lebih mudah maka dibuatlah alur program pada Gambar 12 . 



Gambar 12. Alir program lokal kontrol panel

\section{Sistem Jaringan Ethernet melalui wifi}

Perancangan sistem jaringan ethernet melalui wifi memerlukan modul yang berfungsi sebagai penghubung antara arduino dengan router.

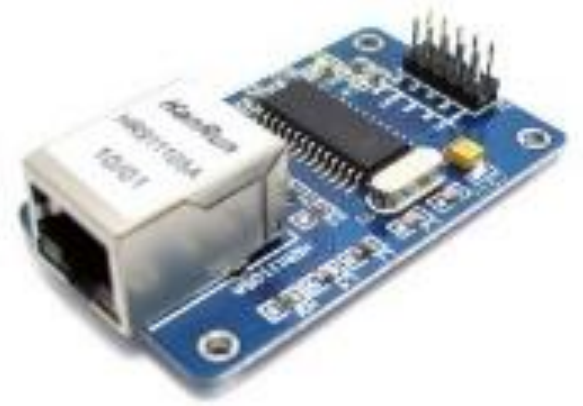

Gambar 13. ENC28J60

Data yang dikeluarkan oleh modbus slave kemudian dirubah menjadi data ethernet melalui modul ENC28J60 kemudian ditransmisikan melalui jaringan wifi melalui router TM-LR 2030.

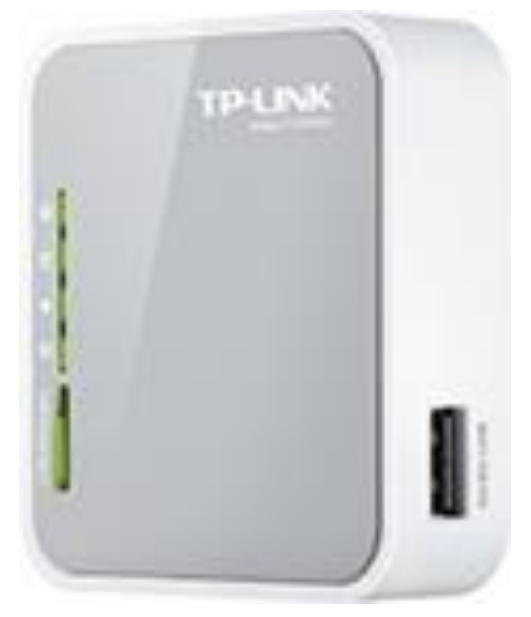

Gambar 14. Router TM-LR 2030

Dari router inilah data antara modbus slave dan master berkomunikasi.

\section{Sistem Modbus dan Remote kontrol panel}

Perancangan sistem modbus mempunyai 2 kelompok besar yang tidak bisa dipisahkan dan harus berpasangan.

\section{Sistem Modbus slave}

Sistem modbus slave merupakan sistem yang sangat diperlukan agar kontrol sistem dapat dioperasikan secara remote. Sistem modbus slave dibangun dari Arduino Mega 2560 yang di dalamnya ditanam program dengan menggunakan library Modbus Arduino yang ditulis oleh André Sarmento Barbosa dan dapat diunduh gratis dari http://github.com/andresarmento/modbusarduino



Gambar 15. Diagram blok modbus slave

Modbus slave dirancang menjadi satu board arduino dengan perangkat keras dari sistem generator set kontrol, hal ini dilakukan karena untuk memaksimalkan kapasitas Arduino Mega 2560. Penerimaan dan pengiriman data dari modbus slave berdasar kepada perintah dari modbus master.

\section{Sistem modbus master}

Modbus master dibagun dari laptop yang berbasis windows 10 yang dapat berkomunikasi melalui wifi. Untuk menjadikan laptop menjadi sebuah modbus master diperlukan sebuah software advancedHMI yang dirancang dari VB.Net 2010 ke atas. Untuk mendapatkan software tersebut dapat diperoleh melalui https://www.advancedhmi.com secara gratis.

Tabel 1. Pengujian lokal kontrol panel

\begin{tabular}{|c|l|c|}
\hline No. & Parameter pengujian & Status \\
\hline 1 & Alarm indikator & OK \\
\hline 2 & Shutdown indikator & OK \\
\hline 3 & Tombol kontrol & OK \\
\hline 4 & Parameter generator set & OK \\
\hline 5 & Status generator set & OK \\
\hline 6 & Buzzer & OK \\
\hline
\end{tabular}


Keuntungan yang didapat jika menggunakan advancedHMI adalah pemrograman dilakukan dengan drag and drop.

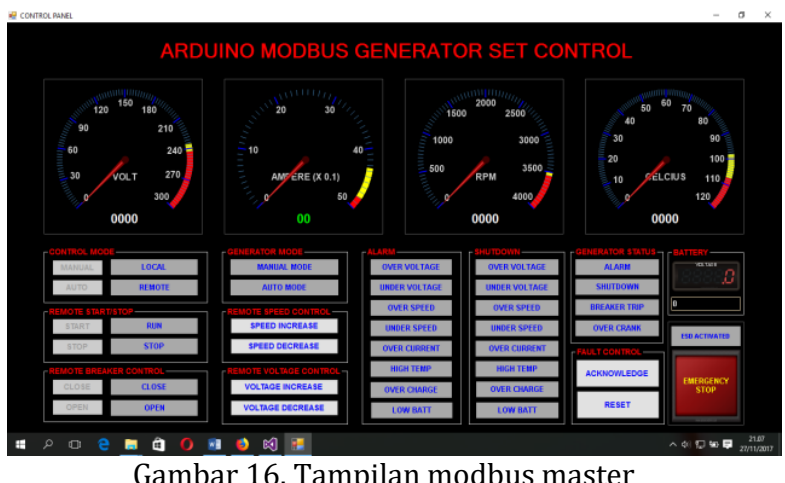

\section{Sistem Governor}

Sistem Governor adalah sistem yang sangat penting karena berhubungan dengan salah kualitas frekuensi keluaran dari generator set. Sebagai basis kontrol dari sistem ini adalah Arduino Nano yang didalamya diprogramkan kontroller logika fuzzy.

Kontroller fuzzy logic mempunyai 7 keanggotaan error, 3 kenggotaan load dan 7 keanggotaan output, masing masing terdiri dari: Keanggotaan speed yaitu :

1. Speed sangat rendah (SSR).

2. Speed rendah (SR).

3. Speed normal rendah (SNR).

4. Speed normal (SN).

5. Speed normal tinggi (SNT).

6. Speed tinggi (ST).

7. Speed sangat tinggi (SST).

Keanggotaan load:

1. Load rendah (LR).

2. Load medium (LM).

3. Load tinggi (LT).

Keanggotaan output:

1. Output sangat rendah (OSR).

2. Output rendah (OR).

3. Output normal rendah (ONR).

4. Output normal (ON).

5. Output normal tinggi (ONT).

6. Output tinggi (OT).

7. Output sangat tinggi (OST).

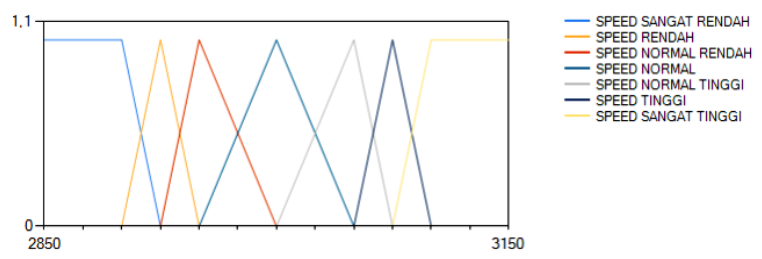

Gambar 17. Keanggotaan Error

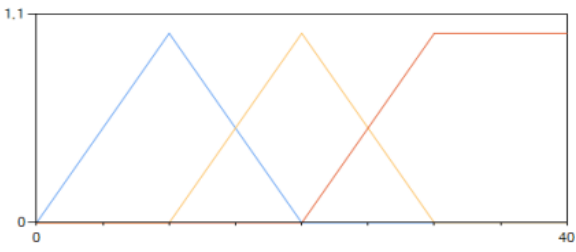

Gambar 18. Keanggotaan load

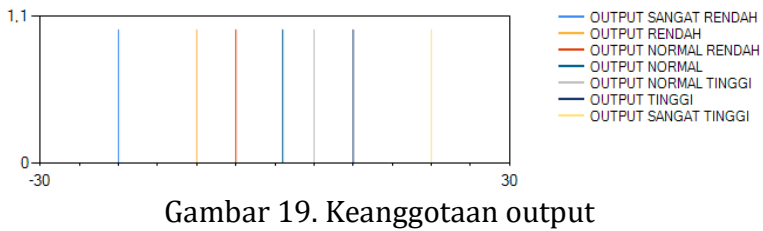

Prinsip kerja dari sistem governor ini adalah nilai dari keluaran fuzzy dijumlahkan dengan nilai setpoint. Nilai dari perhitungan logika fuzzy ini digunakan sebagai keluaran dari governor untuk menggerakkan actuator yang dibangun dari servo motor. Sinyal yang dikeluarkan berupa duty cycle. Duty cycle tersebut akan berubah sesuai dengan perubahan kalkulasi logika fuzzy.



Gambar 20. Diagram blok governor

\section{Sistem Pengatur tegangan(AVR)}

Sistem pengaturan tegangan (AVR) dibagun dengan basis Arduino Nano yang didalamya ditanam kontroller logika fuzzy. Kontroller logika fuzzy yang dirancang mempunyai 7 keanggotaan Voltage, 3 kenggotaan load dan 7 keanggotaan output, masing masing terdiri dari:

Keanggotaan speed:

1. Voltage sangat rendah (VSR).

2. Voltage rendah (VR).

3. Voltage normal rendah (VNR).

4. Voltage normal (VN).

5. Voltage normal tinggi (VNT).

6. Voltage tinggi (VT).

7. Voltage sangat tinggi (VST).

Keanggotaan load:

1. Load rendah (LR).

2. Load medium (LM).

3. Load tinggi (LT).

Keanggotaan output:

1. Output sangat rendah (OSR).

2. Output rendah (OR).

3. Output normal rendah (ONR).

4. Output normal (ON).

5. Output normal tinggi (ONT).

6. Output tinggi (OT).

7. Output sangat tinggi (OST). 



Gambar 21. Keanggotaan tegangan
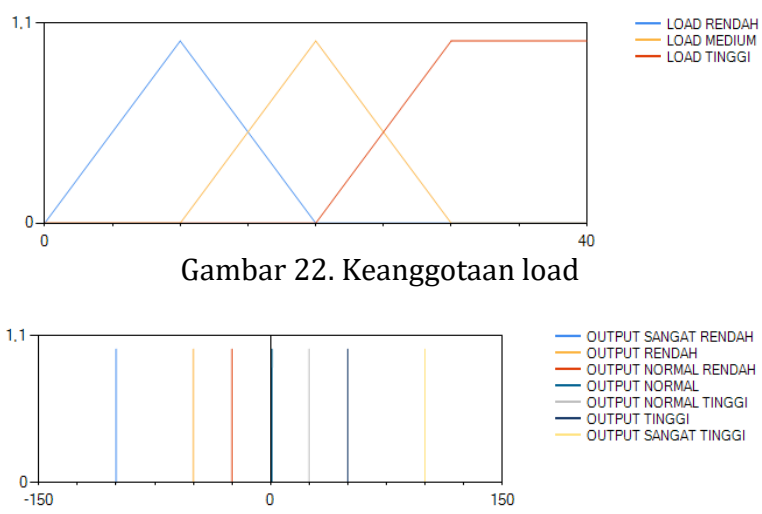

Gambar 23. Keanggotaan output

Keluaran dari logika fuzzy ini digunakan untuk mengatur derajat pemotongan phase.



Gambar 24. Sudut penyalaan tyristor

Dengan dipotongnya derajat penyalaan phase maka tegangan dapat dikontrol melalui rangkian phase control.

Berikut Gambar 25 diagram blok dari sistem pengatur tegangan.

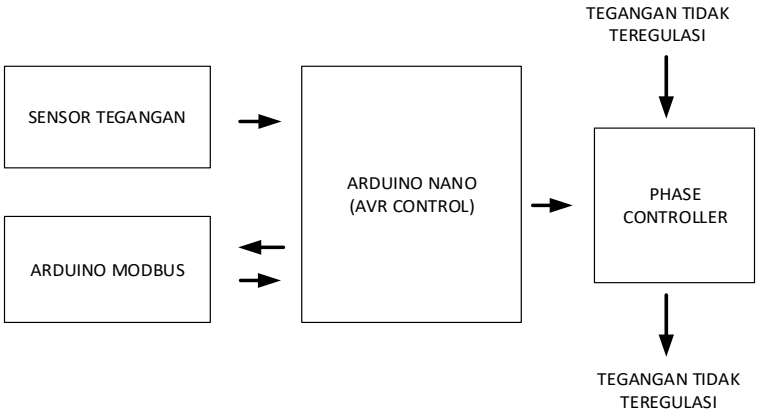

Gambar 25. Diagram blok sistem pengatur tegangan

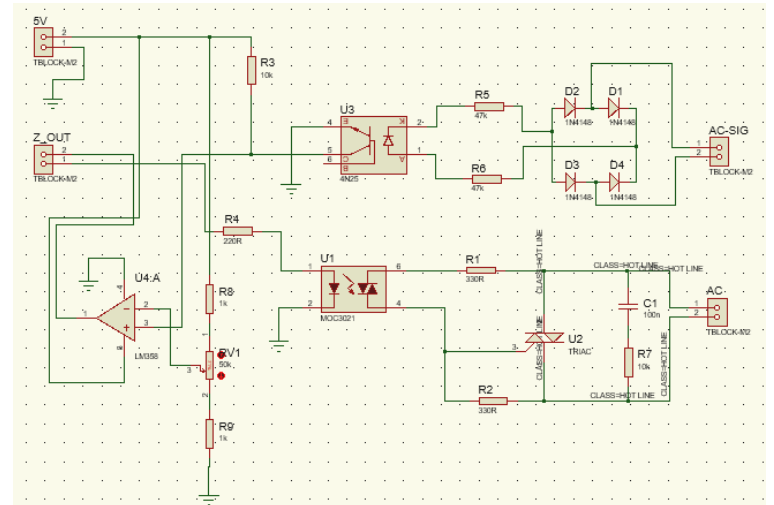

Gambar 26. Schematic phase control

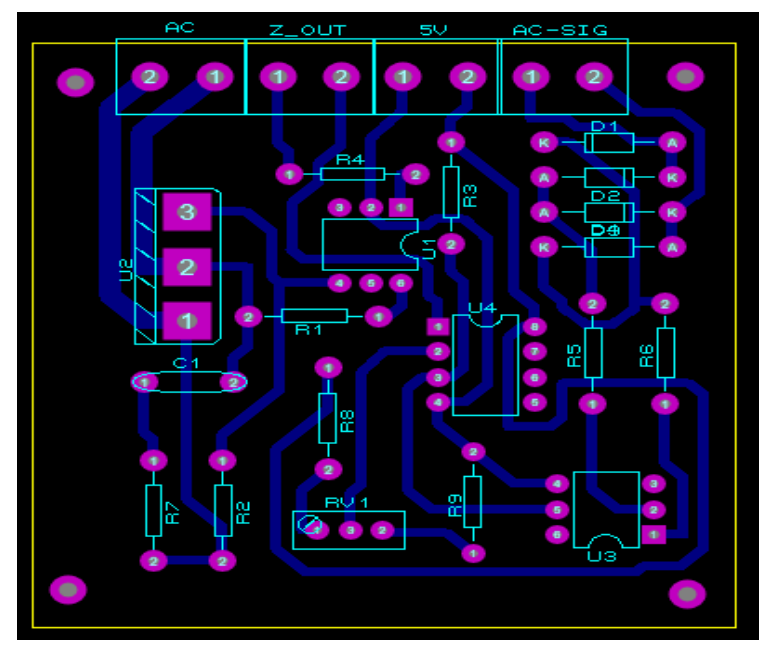

Gambar 27. PCB Phase control

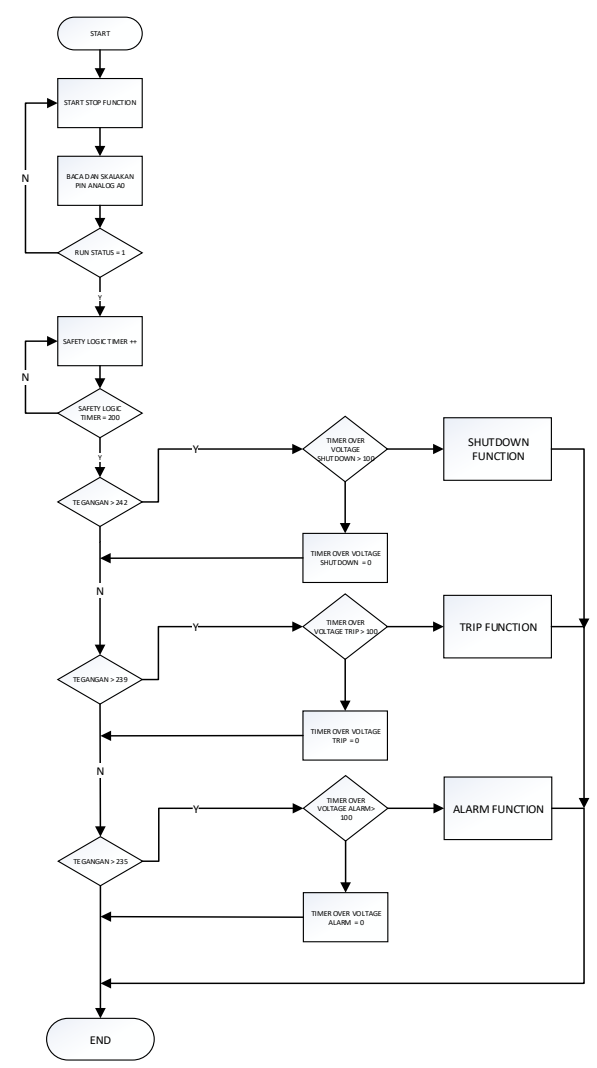

Gambar 28. Diagram alir sistem proteksi 


\section{Sistem generator set protection}

Sistem ini dibangun menggunakan Arduino Mega 2560. Sistem ini menjadi satu papan Arduino Mega 2560 dengan sistem pengontrol mesin penggerak dan sistem pengontrol generator. Sistem proteksi generator set mengambil parameter tegangan AC, tegangan DC, Arus pemakaian, kecepatan putar mesin dan juga temperatur mesin. Jika salah satu parameter melebihi atau kurang dari nilai yang tetapkan program, maka sistem ini akan memerintahkan sistem untuk mengeluarkan alarm atau bahkan mematikan mesin penggerak.

\section{HASIL DAN PEMBAHASAN}

\section{Pengujian power supply}

Pengujian power supply dikaukan dengan memberikan masukan sebesar 12 volt sampai 18 volt, dengan target yaitu keluaran tetap stabil maksimum 14,5 volt untuk regulator pengisian battery, sedangkan untuk regulator 7,5 volt keluaran diharapkan tetap di range 7-8 volt. Untuk regulator 5 volt tegangan diharapkan dengan rentang antara $4,4-5,5$ volt.



Gambar 29. Pengujian power supply

Tabel 2. Pengujian power supply

\begin{tabular}{|c|c|c|c|}
\hline \multirow{2}{*}{$\begin{array}{l}\text { Tegangan } \\
\text { input (V) }\end{array}$} & \multicolumn{3}{|c|}{ Output } \\
\hline & $\begin{array}{l}\text { Battery } \\
\text { Charger }\end{array}$ & $\begin{array}{c}\text { 7,5 V } \\
\text { Module }\end{array}$ & $\begin{array}{c}5 \mathrm{~V} \\
\text { module }\end{array}$ \\
\hline 12 & 11,5 & 7,5 & 5 \\
\hline 13 & 12,5 & 7,5 & 5 \\
\hline 14 & 13,5 & 7,5 & 5 \\
\hline 15 & 14 & 7,5 & 5 \\
\hline 16 & 14 & 7,5 & 5 \\
\hline 17 & 14 & 7,5 & 5 \\
\hline 18 & 14 & 7,5 & 5 \\
\hline
\end{tabular}



Gambar 30. Generator set kontrol sistem

\section{Pengujian Sistem Pengontrol generator set}

Pengujian sistem generator set dapat dilakukan dengan terpasang didalam sistem. Jika dengan metode ini tidak memerlukan jumper kabel. Untuk mengamati dari keluaran sistem pengontrol generator set dapat dilihat secara langsung di led isolator modul. Sedangkan untuk mengoperasikan sistem ini dapat dilakukan dari pengoperasian tombol yang telah dipasang di lokal kontrol panel.



Gambar 31. Tombol pengoperasian

Setelah beberapa kali pengujian didapatkan hasil pengujian yang mendekati alir program. Berikut Tabel 3 pengujian sistem generator set kontrol sistem.

Tabel 3. Pengujian lokal kontrol panel

\begin{tabular}{|c|l|c|}
\hline No. & Parameter pengujian & Status \\
\hline 1 & Alarm indikator & OK \\
\hdashline 2 & Shutdown indikator & OK \\
\hline 3 & Tombol kontrol & OK \\
\hline 4 & Parameter generator set & $\mathrm{OK}$ \\
\hline 5 & Status generator set & $\mathrm{OK}$ \\
\hline 6 & Buzzer & $\mathrm{OK}$ \\
\hline
\end{tabular}

\section{Sistem Jaringan Ethernet melalui wifi}

Pengujian untuk sistem ini harus mempunyai syarat Wifi harus sudah menyala dan terhubung dengan jaringan antara laptop dengan router. Pengaturan alamat IP harus dikonfigurasi sebagai DHCP. Setelah semua persaratan telah terpenuhi maka jaringan wifi diuji dengan menggunakan command promp yang disediakan oleh windows. Untuk melakukan test bukalah command promp dengan perintah CMD

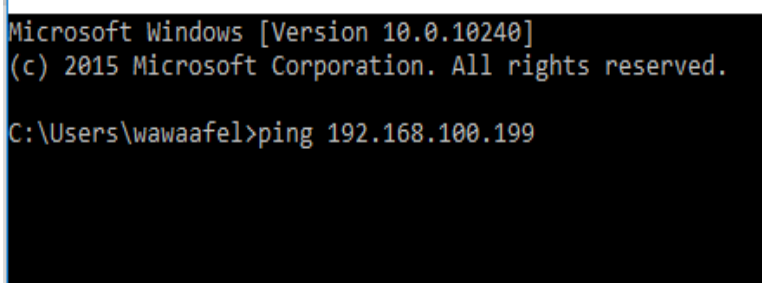

Gambar 32. Layar command promp

Setelah layar command promp tampil ketikkan ping IP Adress di Modbus dan setelah itu akan tampil beberapa statement di layar, jika di layar tampil statement sucess berarti jaringan telah terhubung. Pengujian dilakukan hanya 
mampu mentransmisikan data secara baik dengan jarak maksimum 20 meter.

\section{Sistem modbus}

Pengujian sistem modbus dilakukan dengan metode yang digunakan adalah try and error dengan device terpasang didalam sistem.
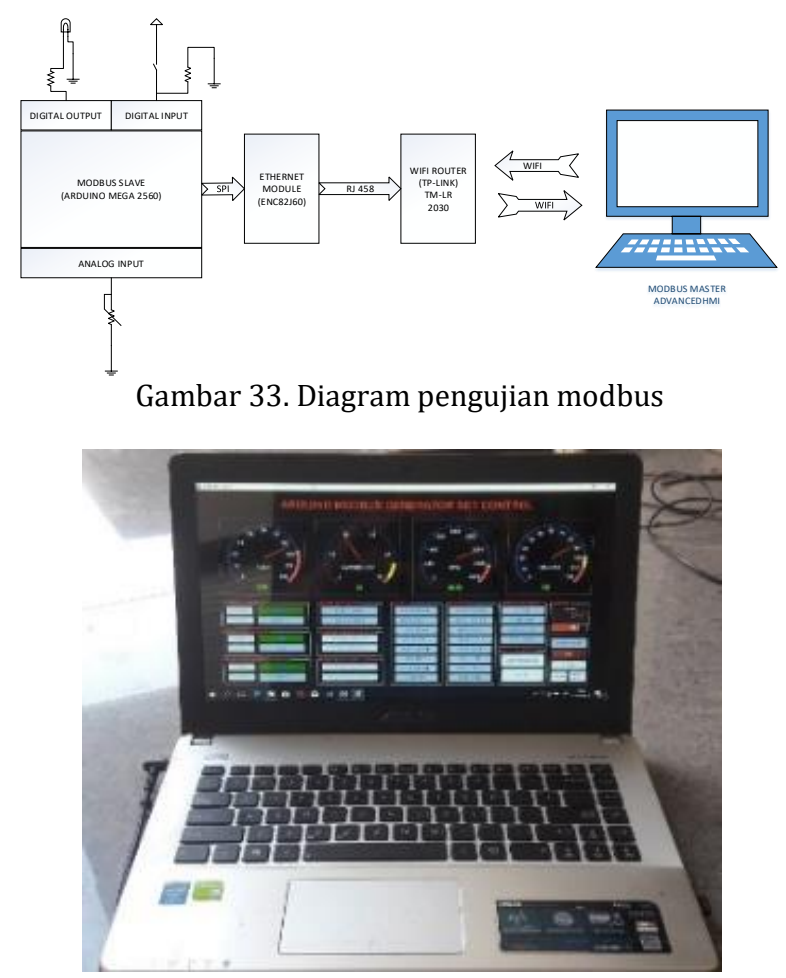

Gambar 34. Laptop sebagai modbus master

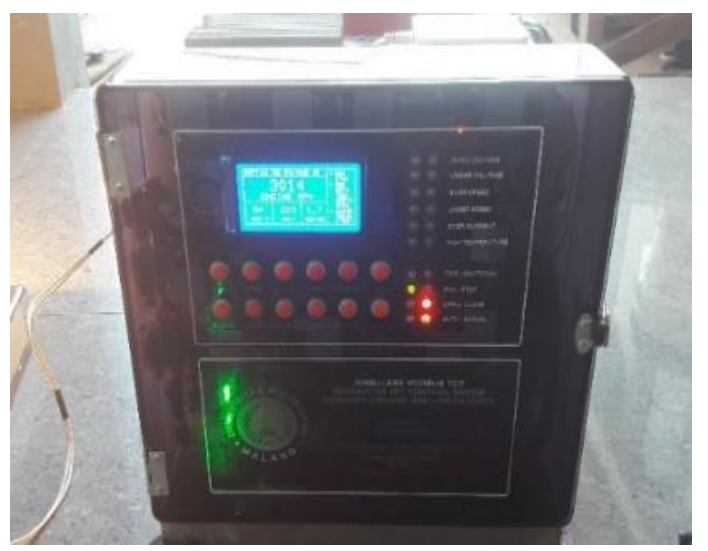

Gambar 35. Tampilan lokal kontrol panel

Dalam pengujian sebagai simulasi masukan digital input maka diperlukan kabel jumper yang dihubungkan dengan terminal positip battery, sedangkan untuk analog input digunakan tahanan geser sebagai masukan simulasinya.

Dari hasil pengujian yang dilakukan alamat modbus master harus ditambah 1 dikarenakan siistem modbus yang dipakai adalah modbus ganjil, sehingga tidak terjadi error saat mengirim dan menerima data

\section{Sistem Governor}

Pengujian sistem governor set dilakukan dengan pembebana terhadaap generator set. Beban yang digunakan adalah load bank yang dibangun dari 4 lampu pijar 100 watt dan 4 lampu pijar 25 watt sehingga total 500 Watt.

Tujuan dari pengujian sistem governor adalah untuk mencari nilai kesetabilan dan transient kecepatan putaran mesin pada saat beban tiba-tiba dinaikkan dan beban tiba-tiba diturunkan. Berikut Tabel 4 adalah hasil pengetesan kecepatan putaran generator set dan pembebanan.

Tabel 4. Pengujian transient governor

\begin{tabular}{|c|c|c|c|c|}
\hline No & Load(A) & Start & Finish & Transient \\
\hline 1 & $0,0-0,6$ & $16.30,95$ & $16.33,69$ & $00.02,74$ \\
\hline 2 & $0,6-1,3$ & $17.12,30$ & $17.13,72$ & $00.01,42$ \\
\hline 3 & $1,3-1,8$ & $17.44,57$ & $17.46,20$ & $00.01,63$ \\
\hline 4 & $1,8-2,3$ & $18.14,86$ & $18.16,39$ & $00.01,53$ \\
\hline 5 & $2,3-2,0$ & $18.45,61$ & $18.47,12$ & $00.01,51$ \\
\hline 6 & $2,0-1,5$ & $19.15,67$ & $19.18,74$ & $00.03,07$ \\
\hline 7 & $1,5-0,7$ & $19.45,64$ & $19.49,15$ & $00.03,51$ \\
\hline 8 & $0,7-0,0$ & $20.22,94$ & $20.28,30$ & $00.05,36$ \\
\hline \multicolumn{4}{|c}{ Transient Rata rata } & $00.02,59$ \\
\hline
\end{tabular}

\section{1,8 - 2,3 Ampere}

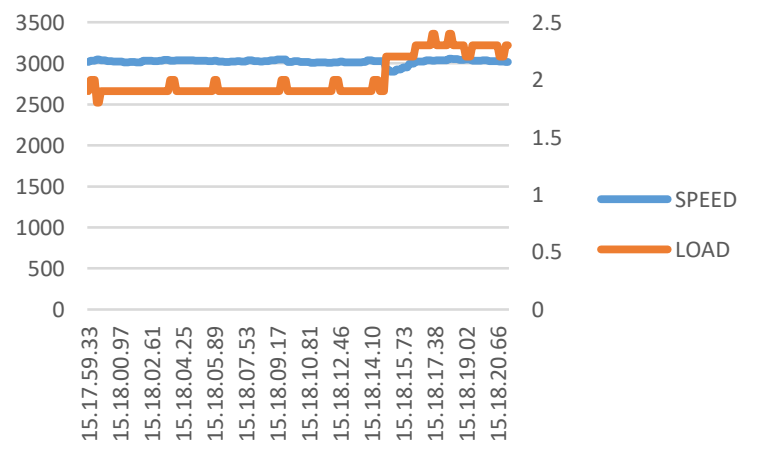

Gambar 36. Transient governor

Dari hasil pengujian transient rata-rata terbaik adalah 2 detik 59 milisecond.

\section{Sistem regulator tegangan keluaran (AVR)}

Pengujian sistem ini dilakukan setelah pengujian Governor selesai dilakukan. Pengujian ini dilakukan untuk mendapatkan kesetabilan tegangan keluaran dalam berbagai kondisi beban dan kecepatan putaran mesin penggerak.

Dari hasil pengujian AVR didapatkan data sebagai tercantum dalam Tabel 5.

Tabel 5. Data pengujian AVR

\begin{tabular}{|c|c|c|}
\hline \multicolumn{3}{|c|}{ STABILITY } \\
\hline Min Rpm & Max Rpm & Fluktuasi \\
\hline 2930 & 3125 & 3 Volt \\
\hline
\end{tabular}

Dari hasil pengujian maka didapatkan kesimpulan bahwa generator set akan mengeluarkan tegangan sampai dengan tegangan 
siap pakai yaitu selama 1 detik 86 milisecond. Dan untuk kesetabilan tegangan keluaran dengan kecepatan putaran mesin yang berubah didapatkan tegangan sebesar \pm 3 Volt.

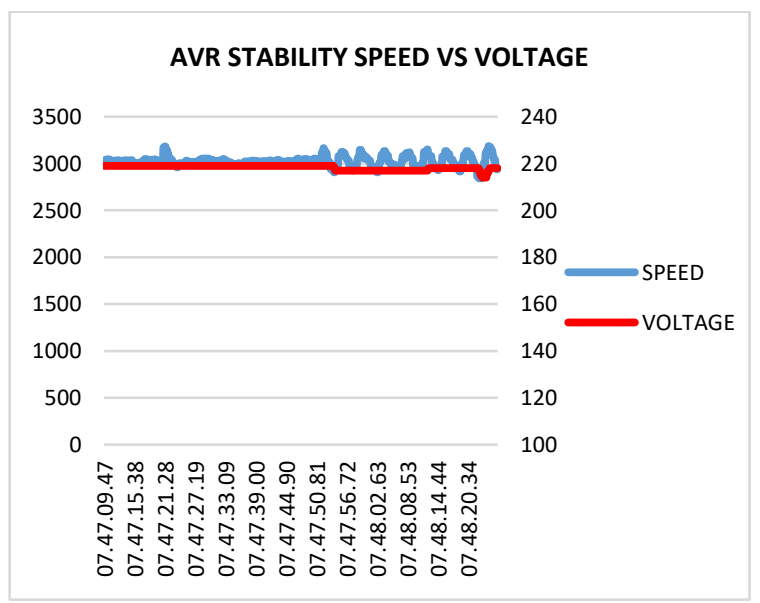

Gambar 37. Kesetabilan speed vs tegangan

\section{Sistem proteksi generator set}

Pengujian sistem ini bertujuan mendapatkan nilai aktual dari sistem proteksi generator set. Pengujian sistem ini dilakukan secara aktual dengan nilai setting diturunkan atau dinaikkan sebesar 10\%, sehingga tidak membahayakan generator set dan pemakai.

\section{Pengujian sistem secara keseluruhan}

Pengujian sistem secara keseluruhan bertujuan untuk menguji alat secara sistem, dengan memanfaatkan semua fitur yng dimiliki oleh wireless generator set control sistem berbasis modbus TCP dan logika fuzzy.

Pengujian ini dilakukan dalam keadaaan unit beroperasi baik dari lokal panel, remote panel, berbagai mode operasi yang dimiliki, dan juga sebagai mode standby.

\section{PENUTUP}

Berdasarkan perancangan, pengujian dan pengamatan yang telah dilakukan maka dapat disimpulkan bahwa : Pengalamatan modbus master harus ditambah satu, agar komunikasi data dapat berfungsi dengan baik. Jarak komunikasi data yang stabil antara router dengan laptop tanpa penghalang yaitu 20 meter. Semakin kecil nilai output fuzzy yang dimasukkan kedalam logika fuzzy Governor, maka putaran mesin semakin stabil, tetapi response terlalu lambat, sehingga transient speed terlalu besar. Semakin besar nilai output fuzzy yang dimasukkan kedalam logika fuzzy Governor, maka putaran mesin semakin berayun, sehingga response terlalu cepat, akibatnya transient speed semakin besar. Semakin kecil nilai output fuzzy yang dimasukkan kedalam logika fuzzy AVR, maka pengaturan tegangan semakin stabil, tetapi response terlalu lambat, sehingga transient tegangan terlalu besar. Semakin besar nilai output fuzzy yang dimasukkan kedalam logika fuzzy AVR, maka tegangan semakin berayun, sehingga response terlalu cepat, akibatnya transient tegangan semakin besar. Sistem proteksi memerlukan sistem waktu tunda, sehingga masih ada kesempatan untuk melakukan sesuatu terhadap generator set, untuk menghindari generator set tiba-tiba mati.

\section{DAFTAR PUSTAKA}

AdvancedHMI. (2013). Quick Start Guide, A different approach to HMI development. Retrieved from https://sourceforge.net/projects/advanced hmi/postdownload?source=dlp

Anggriani, D. P., \& Kadier, R. E. A. (2012). Pengendalian Frekuensi dengan Menggunakan Kontrol Fuzzy Prediktif pada Simulator Plant Turbin-Generator pada PLTU. Jurnal Teknik ITS, 1(1), A72--A77.

Arifin, Y. (2011). Respon Stabilitas Sistem Yang Menggunakan Governor Konvensional Dan Governor Fuzzy Logic. MEKTEK, 13(1).

Gupta, T., \& Sambariya, D. K. (2017). Optimal design of fuzzy logic controller for automatic voltage regulator. In Information, Communication, Instrumentation and Control (ICICIC), 2017 International Conference on (pp. 1-6). IEEE.

Ishak, E., Hunaini, F., \& Rofii, F. (2016). Sistem pengatur kecepatan motor DC menggunakan PID-MYQPSO (Vol. 8). Politeknik Negeri Malang.

Li, Y. X., Zhang, M. L., Niu, D. M., \& Zhang, X. L. (2012). Design and Implementation of Embedded System Based on Modbus TCP/IP. In Advanced Materials Research (Vol. 532, pp. 667-671). Trans Tech Publ.

Nursalim, N., \& Soeprijanto, A. (2015). Desain Kontroler Primemover Generator dengan Fuzzy Adaptif. In Seminar Nasional Informatika (SEMNASIF) (Vol. 1).

Ontoseno, R. D. H., Haqqi, M. N., \& Hatta, M. (2017). Limitasi Pengguna Akses Internet Berdasarkan Kuota Waktu dan Data Menggunakan PC Router OS Mikrotik. Teknika : Engineering and Sains Journal, 1(2), 125-130. https://doi.org/10.5281/zenodo.1116499

Ren, M. M., Ni, X. C., Pang, B., Li, T., \& Song, Z. M. (2013). Design of wireless data transmission module based on ModBus protocol. In Advanced Materials Research (Vol. 753, pp. 
2548-2552). Trans Tech Publ.

Sukarjadi, Arifiyanto, Setiawan, D. T., \& Hatta, M. (2017). Perancangan dan Pembuatan Smart Trash Bin di Universitas Maarif Hasyim Latif. Teknika : Engineering and Sains Journal, 1(2), 101-110.

https://doi.org/10.5281/zenodo.1116487
Wu, F. (2015). Diesel Engine Running at Constant Speed Base on Fuzzy Control Strategy. In Applied Mechanics and Materials (Vol. 713, pp. 893-896). Trans Tech Publ. 